\title{
FAMÍLIA E SERVIÇO SOCIAL: REFLEXÕES ACERCA DA EXPERIÊNCIA NA UNIDADE DE TERAPIA NEONATAL E PEDIÁTRICA DA UFTM
}

\author{
FAMILY AND SOCIAL WORK: REFLECTIONS ON THE EXPERIENCE IN UNIT \\ CARE OF NEWBORN AND PEDIATRIC UFTM
}

\author{
Rosane Aparecida de Sousa Martins ${ }^{1}$ \\ Marta Regina Farinelli ${ }^{2}$ \\ Karen Aguiar da Costa ${ }^{3}$
}

\begin{abstract}
RESUMO
A hospitalização de um membro familiar em Unidade de Terapia Intensiva, em especial de crianças e adolescentes, caracteriza-se por momentos de angústia, tensão e grande estresse para as famílias e a própria equipe de saúde. Buscou-se captar a caracterização dos arranjos familiares a partir da realidade socioeconômica e cultural brasileira. No âmbito das ações, enfatizou-se o trabalho da equipe de saúde junto às famílias de usuários da Unidade de Terapia Neonatal e Pediátrica do Hospital de Clínicas da Universidade Federal do Triângulo Mineiro, analisando a contribuição da atuação do assistente social neste contexto.
\end{abstract}

PALAVRAS-CHAVE: Família. Saúde. Serviço Social. Equipe Multidisciplinar.

\section{ABSTRACT}

The hospitalization of a family member in the intensive care unit, especially children and adolescents, characterized by moments of anxiety, tension, and great stress for families and their healthcare team. Initially, we tried to analyze the reality of families in Brazil and the relationship with public policy, with emphasis on health policy. Later we tried to capture the characteristics of family structure from the socio-economic and Brazilian culture. Among the actions highlighted in the work of health staff and the families of users of neonatal intensive care unit and pediatric Hospital Clinics of the Federal University of Triângulo Mineiro, analyzing the contribution of the social worker's role in this context.

KEYWORDS: Family. Health. Social Work. Multidisciplinary Team.

\footnotetext{
${ }^{1}$ Doutora em Serviço Social pela UNESP/ Franca. E-mail: rosane@servicosocial.uftm.edu.br, telefone: 553433185947.

${ }^{2}$ Doutora em Serviço Social pela UNESP/Franca, Universidade Federal do Triângulo Mineiro - UFTM. E-mail martaregina@servicosocial.uftm.edu.br.

${ }^{3}$ Mestre em Educação pela Universidade de Uberaba, Hospital de Clínicas da Universidade Federal do Triângulo Mineiro - UFTM. E-mail karenaguiardacosta@yahoo.com.br.
}

Serv. Soc. \& Saúde, Campinas, SP v. 12, n. 2 (16), p. 171-184, jul./dez. 2013 ISSN 1676-6806 


\section{INTRODUÇÃO}

As reflexões apresentadas neste artigo resultam de observações constantes, debates e questionamentos entre os profissionais da Unidade de Terapia Neonatal e Pediátrica do Hospital de Clínicas da Universidade Federal do Triângulo Mineiro e, substancialmente, da experiência como assistente social e professor orientador de projetos de extensão no âmbito desta Unidade.

Este artigo propõe a reflexão sobre o trabalho com famílias, cujos filhos estão internados na referida unidade de saúde a qual dispõe de 20 (vinte) leitos e atende a um público de bebês prematuros e crianças em estado grave.

O atendimento aos usuários (pacientes internados e suas famílias), objetiva promover ações de recuperação e bem estar destes pacientes. O trabalho na unidade é realizado por equipe multidisciplinar composta por médicos, psicólogos, nutricionistas, enfermeiros, terapeutas ocupacionais, fisioterapeutas, fonoaudiólogos e assistentes sociais.

A atuação do assistente social constitui-se de momentos que têm permitido contato direto com a realidade familiar e propiciado a discussão com a equipe de saúde, na busca de definições de estratégias de intervenção, necessárias ao trabalho junto às famílias.

É importante ainda assinalar que se, por um lado, a instituição tem o monopólio do objeto e dos recursos institucionais, se é ela que define o significado objetivo do papel do profissional e a expectativa que existe com relação a ele, por outro lado, é o modo particular, subjetivo, como o profissional elabora a sua situação na instituição, estabelecendo sua própria ordem de relevâncias, que vai dar o sentido do seu trabalho (BAPTISTA,1995, p.113).

Para isso, é preciso compreender a realidade social em que o grupo familiar vive, os movimentos sociais e os processos de transformação em que está inserido. Portanto, neste artigo "trabalhar-se-á com as famílias, no plural, tendo em vista a multiplicidade étnico-cultural, que embasa a composição demográfica brasileira. [...] (NEDER, 1994, p 26).

As transformações societárias das últimas décadas, no Brasil e no mundo, influenciaram mudanças significativas e profundas na concepção de família. Esta 
concepção vem se construindo em cada sociedade e em cada época, de acordo com normas e preceitos culturais, sociais, econômicos e políticos.

O modelo de família baseado no matrimônio e no poder familiar deixou de ser referenciado somente pelo núcleo econômico e de reprodução, passando a abranger outras possibilidades de formação nas relações sociais em que prevalecem o companheirismo, o amor e o afeto.

As mudanças contemporâneas modificaram os referenciais para caracterizar os padrões familiares. Novas configurações estão presentes na dinâmica familiar atual como a união estável, a família unipessoal, monoparental chefiada, em sua maioria, por mulheres, a união homoafetiva e o casamento como laço de vínculo afetivo e jurídico considerado o ato mais solene na formação familiar, entre outras.

A atual multiplicidade de formas, com valores, estilo de vida e práticas particulares, para muitos estudiosos, é uma renovação dos conceitos familiares; para outros, a necessidade de buscar novos modelos adequados às relações de parentesco diversas e às relações sociais com os filhos. Embora não se realize com o mesmo contorno nos vários segmentos sociais, a família, atualmente, resulta de distintas maneiras de articulação das relações familiares, expressas nos diferentes papéis e nas trajetórias de vida de seus membros.

Nesta direção, não se pode esquecer que cada família tem características particulares, valores, formas de linguagem, códigos, entre outros. Desenvolve, entre seus membros, normas próprias, regras de comunicação, relações diferenciadas, hierarquias, jogos e estratégias de luta no enfrentamento das diversas expressões da questão social.

Em relação às expressões da questão social como o aumento da população abaixo da linha da pobreza, desemprego estrutural, dificuldades no acesso à qualificação para o trabalho, desigualdade na distribuição de renda, ausência de efetivação das políticas sociais públicas, e demais questões surgidas na era global, as famílias não têm opção. Resta-lhes, apenas, lutarem por respeito, justiça e solidariedade. Enquanto isso não ocorre, homens, mulheres e crianças morrem nas portas de hospitais, postos de saúde, entre outros, por falta de atendimento. É nessa realidade que atuam os profissionais da área de saúde, em especial, o assistente social.

Paralelamente, observam-se as contradições da Política de Saúde no Brasil. Especificamente na instituição analisada ressalta-se o fato de que o lócus de Serv. Soc. \& Saúde, Campinas, SP v. 12, n. 2 (16), p.171-184, jul./dez. 2013 ISSN 1676-6806 
atendimento da equipe de saúde ocorre em um hospital que é referência em diversos tipos de atendimentos, tecnologia e produção de conhecimento, em uma das regiões mais ricas do Triângulo Mineiro.

Por outro lado, internamente, esse hospital apresenta problemas crônicos como os demais hospitais públicos do país, quanto a vagas para internação ou mesmo problemas relativos à humanização do atendimento, deficiência de projetos preventivos, baixo número de profissionais mediante a demanda atendida, dentre outros.

Em face desse contexto, este trabalho propõe discutir o tema família na perspectiva da atuação profissional do assistente social, contribuindo para a ampliação das produções científicas sobre tal tema, no âmbito da Política de saúde.

\section{A família no âmbito da Política de Saúde}

Observa-se que as famílias convivem com as contradições inerentes às políticas sociais públicas, que têm espelhado diferentes visões de mundo, de interesses, de estrutura social, etc. Ressalta-se que as políticas sociais e a própria política de saúde, muitas vezes, se restringem a ações fragmentadas, esporádicas, que se desenvolvem em virtude de problemas sociais surgidos, com a finalidade de mediatizar ou amenizar conflitos. São programas emergenciais, de caráter paliativo, que não visam a transformação social.

Este quadro reflete o antagonismo da sociedade que promove a desigualdade social em nome, unicamente do desenvolvimento econômico do país. Mediante o estado mínimo instituído com a inserção do neoliberalismo no Brasil; a população encontra-se, cada vez mais, desprotegida pelas políticas sociais públicas, comprometendo o acesso aos direitos sociais.

Verifica-se que os direitos promulgados na Constituição Federal de 1988 têm grande eficiência no papel, mas no tocante à efetivação, ainda há um longo caminho a percorrer para que se alcancem os direitos garantidos, apesar dos significativos movimentos articulados pela sociedade, em favor dos interesses populares. Diante disso, tais ações tornam-se paliativas, de modo que a realidade social se mantém, sem que o problema real se extinga.

O Sistema Único de Saúde (SUS), cuja lei foi promulgada na Constituição Federal de 1988, tem como princípios a descentralização político-administrativa; o Serv. Soc. \& Saúde, Campinas, SP v. 12, n. 2 (16), p. 171-184, jul./dez. 2013 ISSN 1676-6806 
acesso universal e igualitário à saúde, o incentivo à participação da comunidade, preservação da autonomia das pessoas na defesa de sua integralidade física e moral, dentre outros. O SUS foi instituído pela Lei Orgânica de Saúde (Lei no 8080 de 19 de setembro de 1990) que garante a saúde como direito social, por meio de políticas econômicas, sociais, científicas (educação) e tecnológicas, priorizando a promoção do estado de bem-estar físico, mental e social de toda a população.

A Lei Orgânica da Saúde é um novo sistema para o reordenamento dos serviços e ações de saúde, seguindo os mesmos princípios organizadores em todo o território nacional. Por meio de sua elaboração, pretende-se intervir na qualidade de vida da população, passando de um modelo assistencial centrado na doença e baseado no atendimento a quem o procura, para um modelo de atenção integral à saúde e prevenção das doenças, além das ações de recuperação e reabilitação. Essa ação integral envolve controle epidemiológico e vigilância sanitária, ações educativas, preventivas e curativas, saneamento básico, suplemento alimentar, habitação, lazer, transporte, promoção humana, trabalho e integração social, além de controle de zoonoses.

Percebe-se que a proposta da Política de Saúde com base nos referidos documentos é ampla, mas não atendem às reais necessidades demandadas pela população usuários dos serviços de saúde. Isto porque questões como a burocracia, o mau uso dos bens públicos e os interesses de grupos dominantes têm contribuído para a "falência" das políticas sociais públicas. Assim, um dos desafios da saúde é colocar o interesse do paciente-usuário à frente do SUS, centralizando seus objetivos na qualidade dos serviços prestados e na humanização do atendimento em saúde.

$\mathrm{Na}$ área das políticas da saúde, o trabalho com famílias, durante muito tempo, se restringiu ao Programa de Planejamento Familiar. Ao invés de uma ação integrada às políticas públicas voltadas para a promoção do indivíduo e de sua família, têm sido desenvolvidas ações que atendem às famílias fragmentando suas demandas por segmentos. Entre eles destaca-se a saúde da mulher, saúde do idoso, saúde do trabalhador, saúde da criança e do adolescente como alguns dos segmentos priorizados pelo Estado em detrimento de uma proposta de atenção integral à saúde.

Neste contexto, pode-se afirmar que a família tem sido uma ilustre desconhecida no âmbito das políticas públicas brasileiras que reforçam ações fragmentadas e focadas na responsabilização das famílias pelos diversos problemas por elas vivenciadas. 
A promoção e o apoio às famílias, sobretudo aquelas em situação mais vulnerável, e o reconhecimento das mesmas enquanto agente social ativo e objeto de políticas públicas, constituem-se em fatores decisivos na busca dos objetivos prioritários do desenvolvimento humano, tais como a eliminação da pobreza, o acesso à saúde, a educação e a alimentação, a erradicação do trabalho infantil, a promoção da igualdade entre os gêneros e a proteção integral a seus membros, das crianças aos idosos [...] O Brasil, cada vez mais urbano, vem sendo marcado por profundas transformações sociais, econômicas, culturais, éticas e mesmo ao nível do comportamento humano. Permanece, contudo, um consenso em torno da família como espaço privilegiado para a prática de valores comunitários e o aprofundamento de relações de solidariedade. Reitera-se também a permanência de suas funções, consideradas insubstituíveis quanto à assistência, promoção de valores, educação, proteção aos seus membros e, sobretudo, lugar de encontro de gêneros e gerações (MAURÁS, KAYAYAN, 1994, p.10).

A atenção à família deve considerar a realidade social em que está inserida, bem como seu movimento diante das mudanças da sociedade e seu acesso às políticas sociais públicas. Ao mesmo tempo, a família também necessita ser empoderada em termos socioeconômicos, culturais, psicoemocionais e jurídicos, para que assuma e pratique a proteção à sua prole. O potencial protetivo das famílias tem que ser estimulado para que possam expandi-lo.

A complementação da renda familiar, apoio psicossocial e advocatício, educação popular e capacitação profissional são alguns dos programas movidos para atender ao conjunto de demandas portadas pela família em seu processo de fortalecimento emancipatório. A retomada da família num cenário de partilha de responsabilidades com o Estado, sociedade e iniciativas privadas, aliada ao fortalecimento da gestão local (municípios) desenham o novo projeto de proteção social deste final de século (CARVALHO, 1997, p. 11).

Este tema é instigante e desafiador para todos os profissionais da saúde e, principalmente, pelo fato que esse caminho está totalmente aberto à atuação em equipe multiprofissional ou interdisciplinar. Refletir sobre as mudanças na família é tarefa de todos, sobretudo de profissionais que lidam diariamente com ela. As transformações ocorridas no seio familiar estão imbricadas nas mudanças da sociedade, assim como diversas mudanças da sociedade derivam dos novos arranjos familiares. 


\section{Refletindo sobre os novos arranjos familiares}

Há, atualmente, diversos arranjos e caracterizações da família nas diferentes classes sociais. A maior participação da mulher no mercado de trabalho, o empobrecimento, baixos salários, incentivo ao consumo, altas taxas de desemprego, a violência, as questões relacionadas ao uso de drogas e de álcool são alguns fatores que contribuíram para as novas configurações familiares.

Por outro lado, observa-se a ocorrência de movimentos no sentido de se "adaptar" ou de superar a realidade social a qual estão expostas grande número de famílias. Assim, surge uma diversidade de formas e de características dos grupos familiares, uma vez que a participação das famílias não ocorre de maneira uniforme. Cada uma tem aspectos diferenciados que conduzirão ou não a adaptação ao atual contexto social ou ao seu enfrentamento.

No Brasil, prevalece, ainda, um conceito de família referenciado no "modelo nuclear burguês", constituída de pai, mãe e filhos vivendo numa mesma casa e, em geral, tendo acesso aos bens e recursos necessários ao desenvolvimento do ser humano em sua totalidade. As famílias que não se encaixam neste "modelo", muitas vezes, são classificadas como "desestruturadas", "portadoras de problemas", “incompletas". A estrutura familiar ou sua configuração ainda é a base de análise dos núcleos familiares.

Cotidianamente, atribui-se à família a responsabilidade pelos problemas emocionais, distúrbios de comportamento, rebeldia, fragilidade e inserção em grupos considerados "marginais" como gangues, usuários de drogas, "pichadores" e as diversas formas que tomam a denominada "delinquência".

A família tem sido objeto de um discurso conservador como se pode observar na esfera religiosa, em escolas que seguem uma linha mais conservadora de ensino, a mídia que é outro instrumento que veicula as formas certas e erradas dos fatos da vida, de acordo com o interesse em voga, dentre outras.

Os próprios profissionais da saúde "algumas vezes", atuam apresentando o "modelo" certo de família e as rotinas e as responsabilidades de cada membro no cuidado. Em geral, os "modelos" são transmitidos por todas as fontes citadas e são assimilados pelas famílias. Como consequência, as famílias sentem-se incompetentes, inferiorizadas, incapacitadas por não conseguirem viver de acordo com o modelo apresentado como "ideal". Tudo isso se desenvolve em meio ao contexto familiar, mas 
entrelaçado às determinações sociais. Desta forma, a família é, ao mesmo tempo, o espaço de criação e definição das alterações na sociedade, mas é também o local de reprodução das diversas manifestações e transformações da mesma sociedade.

O mundo familiar mostra-se numa vibrante variedade de formas de organização, com crenças, valores e práticas desenvolvidas na busca de soluções para as vicissitudes que a vida vai trazendo. Desconsiderar isso é ter a vã pretensão de colocar essa multiplicidade de manifestações sob a camisa-de-força de uma única forma de emocionar, interpretar, comunicar (SZYMANSKI, 1995, p. 27).

Essas alterações derivam dos vários movimentos da própria família e da sociedade em que está inserida. Entre eles, podem-se citar as modificações de valores morais, hábitos, costumes, principalmente relativos à posição da mulher na sociedade em termos de mercado de trabalho e em relação à sua sexualidade; mudanças nos papéis e hierarquias, desenvolvimento industrial, acelerada urbanização e êxodo rural; empobrecimento em massa, seguido de exclusão em todos os níveis; desemprego; deficiência das políticas sociais públicas no atendimento das necessidades básicas da população; afastamento da participação do Estado nas expressões da questão social, avanço dos meios de comunicação e massificação das informações; aumento da desigualdade social, econômica, espacial, cultural, educacional e étnicas.

Para que o trabalho com famílias seja veículo de mudanças efetivas no espaço social, é necessário refletir sobre os modelos assistenciais dentro dos quais este trabalho se desenvolve. Isto para avançar de uma posição de tutela e controle para uma condição de parceria e cidadanização das famílias (MIOTO,1997, p. 128).

\section{Desafios e perspectivas no contexto da Política de Saúde: o trabalho junto às}

\section{famílias}

$\mathrm{Na}$ perspectiva de aprofundar o conhecimento sobre o trabalho profissional do assistente social no campo da família, a observação participante do ambiente hospitalar, especialmente da Unidade de Terapia Neonatal e Pediátrica e a orientação dos acadêmicos em projetos de extensão e de intervenção na área de Serviço Social, elaborados no âmbito do Hospital de Clínicas da Universidade Federal do Triângulo Mineiro, foram fundamentais e contribuíram, decisivamente, para o desvendamento dessa realidade. 
Este artigo se pauta na análise do atendimento direto das famílias de pacientes internados, das limitações e deficiências desse atendimento e, especialmente, sobre a perspectiva de atuação do assistente social junto às famílias no cotidiano desta unidade.

A instituição, lócus de análise apresenta fragilidades tais como a inexistência de local para alojamento de familiares junto ao paciente, normas rígidas impedindo o direito da família, acompanhar ou visitar o paciente, falta de preparo dos profissionais que atendem o paciente para apoiarem e orientarem as famílias, os insuficientes recursos da comunidade para atendimento, transporte e alojamento de famílias procedentes de outros municípios, falta de oportunidade de encontro da equipe para traçar ações efetivas para as angústias vivenciadas ocasionadas pela ausência da família junto ao paciente, dentre outros.

As famílias estão se deparando com sérios desafios advindos tanto de suas demandas internas como de seu meio social. À medida que não conseguem soluções adequadas para os desafios, elas expressam suas dificuldades por meio de inúmeros problemas (dificuldades de relacionamento, membros-problema, doenças). A compreensão desses problemas dentro da ótica apontada coloca como fundamental o deslocamento do eixo do atendimento das dificuldades individuais para os familiares (espaço institucional, modelo assistencial, políticas sociais), para que estes possam colocar a família e não os seus membros individualmente no centro de suas propostas (MIOTO,1997, p. 128).

É possível também identificar as inúmeras dificuldades e limitações no atendimento direto às famílias, carência de recursos materiais e financeiros para satisfazer as necessidades concretas das famílias com pacientes internados, excesso de trabalho da equipe de saúde devido a precariedade do número de profissionais técnicos, impossibilitando o aprofundamento na intervenção junto às famílias, fragilidades da formação na graduação com ausência da discussão de temáticas relacionadas a humanização na saúde, bem como a deficiência na relação interdisciplinar que dificulta o trabalho integrado na assistência à família na totalidade.

Quanto aos processos de atenção à família nos espaços institucionais é necessário dizer inicialmente que, em sua maioria, estão organizados para trabalhar na perspectiva do usuário-problema. Ou seja, o usuário privilegiado é a criança, o adolescente, a mulher, o idoso dentro de situações específicas, tais como a doença, a delinquência, o abandono, os maus-tratos. Dessa organização institucional deriva um modelo assistencial cuja preocupação central é a resolução dos problemas de seu usuário. Este modelo, embora cada vez mais sofisticado em termos de recursos disponíveis para a intervenção (tanto técnicos, como 
profissionais), tem uma leitura limitada das demandas que lhe são colocadas (MIOTO,1997, p.123).

Muitas vezes, as famílias procuram o setor de Serviço Social como ponto de apoio para superar as dificuldades mencionadas, acreditando que estes profissionais são capazes de solucionar seus problemas.

O Serviço Social do Hospital de Clínicas da Universidade Federal do Triângulo Mineiro tem como missão prestar atendimento social aos usuários, incentivando-os a participarem na busca da saúde, por meio do conhecimento de alternativas de mudanças nas situações sociais que possam interferir no processo saúde-doença.

O trabalho do assistente social está pautado no Código de Ética Profissional aprovado em 1993, vinculado a um projeto de transformação da sociedade, atuando no espaço contraditório das classes sociais com reconhecimento de liberdade como valor ético central e das demandas políticas a ela iminentes, autonomia, emancipação e plena expansão dos indivíduos sociais.

Neste contexto, o trabalho do assistente social contribui, diretamente, para que os usuários e seus familiares possam lutar pelo acesso aos seus direitos garantidos pela Constituição Federal de 1988, reconhecendo a saúde como um direito de todos e um dever do Estado por meio de ações de proteção, prevenção, promoção, recuperação e reabilitação da saúde.

É por meio do trabalho do assistente social junto à equipe multidisciplinar de saúde, que se conseguem traçar estratégias de ação, buscando alternativas para atender e suprir as demandas e necessidades das famílias e dos pacientes atendidos na Unidade de Terapia Neonatal e Pediátrica do Hospital de Clínicas da Universidade Federal do Triangulo Mineiro.

A atuação do assistente social tem como objetivo conhecer a realidade vivenciada pelos usuários da Unidade e respectivas famílias, planejando e realizando um trabalho articulado com a equipe profissional através de ações qualificadas e éticas voltadas para atender as necessidades e demandas dos usuários (pacientes e familiares).

Para tanto, o trabalho é desenvolvido por um assistente social, 02 estagiários do Serviço Social, 05 acadêmicos do curso de Serviço Social inseridos no projeto de extensão - Humanização da Unidade de Terapia Intensiva Neonatal e Pediátrica, sob o acompanhamento de dois docentes da área de Serviço Social da Universidade.

Serv. Soc. \& Saúde, Campinas, SP v. 12, n. 2 (16), p. 171-184, jul./dez. 2013 ISSN 1676-6806 
As ações, no âmbito do Serviço Social, têm como perspectiva conhecer a realidade social e perfil dos usuários pela caracterização dos pacientes e familiares atendidos na unidade; veicular informações e conhecimentos aos familiares sobre o processo de internação, a rotina hospitalar e os direitos sociais dos pacientes e familiares no âmbito da saúde, bem como buscar alternativas para melhoria da qualidade de vida dos familiares dos pacientes internados, possibilitando-lhes o acesso aos seus direitos enquanto cidadão.

Deste modo, o trabalho profissional do assistente social na Unidade de Terapia Intensiva Neonatal e Pediátrica ocorre por meio de entrevista e acolhimento diário às famílias e responsáveis, escuta, veiculação de informações sobre os direitos sociais, através dos programas e políticas sociais; contatos familiares individuais ou grupo (sala de espera) para esclarecer dúvidas, troca de informações e acompanhamento dos casos dos pacientes; participação em reuniões com os outros profissionais da saúde da Unidade para traçar ações em equipe e avaliação do trabalho profissional do Serviço Social, visitas domiciliares, visitas institucionais e contatos externos a recursos de comunidade e a outros serviços, conforme as demandas apresentadas pela equipe de saúde e pelos usuários do serviço, quando necessário.

\section{CONSIDERAÇÕES FINAIS}

O período de hospitalização é um momento extremamente delicado e um desafio para pacientes, familiares e para os próprios trabalhadores da saúde. Neste contexto, o trabalho do assistente social com as famílias pode contribuir, decisivamente, para a superação destes desafios, pois tem como premissa o trabalho em equipe e o desenvolvimento de ações com enfoque na integralidade da saúde, na qualidade dos serviços prestados e na humanização dos atendimentos.

No espaço hospitalar é possível identificar famílias marcadas pela diversidade cultural, econômica e social evidenciando os novos arranjos familiares existentes no país. Por outro lado, existem profissionais que ainda mantêm uma visão única e padronizada de família ideal e que percebem a alteridade como sinônimo de inferioridade, e não de diferença ou singularidade. Tais situações interferem, diretamente, no trabalho da equipe de saúde junto às famílias.

$\mathrm{Na}$ proposta de atendimento às famílias, é extremamente importante o papel da equipe. Reconhece-se que o trabalho de médicos, enfermeiros, assistentes sociais, Serv. Soc. \& Saúde, Campinas, SP v. 12, n. 2 (16), p. 171-184, jul./dez. 2013 ISSN 1676-6806 
fisioterapeutas, dentre outros, realizado em equipe pode contribuir para a atenção ampla ao paciente e sua família, no tratamento, tanto no âmbito da saúde, quanto nas áreas social e cultural, respeitando a singularidade de cada usuário e família, até mesmo fora do contexto hospitalar.

É importante salientar, especialmente, a contribuição do trabalho em equipe para o fortalecimento das ações junto às famílias na Unidade. Por meio da identificação da necessidade de ampliação das ações no âmbito da Humanização Hospitalar, a equipe de saúde retomou o projeto de Humanização em Unidade de Terapia Intensiva Neonatal e Pediátrica do Hospital de Clínicas da Universidade e formalizou o grupo de humanização que tem entre os profissionais, o assistente social.

A partir do trabalho de todos os profissionais da equipe de saúde da Unidade, aliado ao projeto de humanização, identificam-se avanços como fortalecimento do trabalho em equipe, organização do local para alojamento das mães, próximo ao paciente, reestruturação das normas de visitação ao paciente, ações de formação continuada dos profissionais que atendem o paciente para apoiar e orientar as famílias, criação de projetos de acolhimento às famílias, projeto de acompanhamento e visitas dos irmãos e desenvolvimento de ações específicas para que a infraestrutura na Unidade ofereça assistência de excelência aos pacientes e família.

Além disto, destaca-se a relevância da atuação do Serviço Social na garantia da participação social das famílias no processo de recuperação e prevenção de doenças e promoção da saúde, por meio de atividades de sala de espera, acolhimento e entrevistas iniciais e de acompanhamento das famílias de pacientes internados, atividades de pesquisa e extensão voltados para o desvelamento da realidade social dos usuários da saúde e a identificação de estratégias de enfrentamento das expressões da questão social vividas por usuários que compõem a classe trabalhadora no Brasil.

$\mathrm{O}$ trabalho do assistente social, junto às famílias, tem contribuído para $\mathrm{o}$ planejamento e implantação de ações que interferem, diretamente, nos determinantes sociais, no processo saúde/doença e no reconhecimento da saúde como direito social de toda a população.

Reconhece-se, também, a contribuição do trabalho do assistente social no estabelecimento de estratégias de ampliação e universalização dos direitos sociais, na politização dos espaços públicos de atenção à saúde, no sentido de atender aos interesses e necessidades da população usuária dos serviços de saúde. Serv. Soc. \& Saúde, Campinas, SP v. 12, n. 2 (16), p. 171-184, jul./dez. 2013 ISSN 1676-6806 
É fundamental que o assistente social, e toda a equipe de saúde, mantenham uma visão ampla e de totalidade no contexto hospitalar e busquem realizar uma leitura crítica da sociedade, estabelecendo a relação entre os aportes teóricos e a realidade social. Ou seja, criar espaços de discussão sobre as perspectivas de análise da família contemporânea que iluminem o trabalho cotidiano com as mesmas, no âmbito hospitalar.

$\mathrm{Na}$ mesma direção, ressalta-se a necessidade de que os profissionais que atuam na Unidade de Terapia Intensiva Neonatal e Pediátrica fortaleçam o compromisso com a implantação de projetos que considerem a questão social, a melhoria da qualidade de vida e o desenvolvimento da cidadania dos usuários dos serviços de saúde, em especial das famílias cujos membros encontram-se em tratamento.

\section{REFERÊNCIAS}

ACOSTA, A. R.; VITALE, M. A. F. (Orgs). Família: redes, laços e políticas públicas. São Paulo: IEE/PUCSP, 2003.

BAPTISTA, M.V. A ação profissional no cotidiano. In: MARTINELLI, M. L., ON, M. L.; MUCHAIL S. T. (Orgs.). $\mathrm{O}$ uno e o múltiplo nas relações entre as áreas do saber. São Paulo: Cortez, 1998, p. 110-121.

CARVALHO, M.C.B. O lugar da família na política social. São Paulo: 1997 (mímeo).

GUIDO, I.C.; SANTOS, L. Sistema Único de Saúde. 2a . Ed. São Paulo: HUCITEC, 1995.

MAURÁS, M; KAYAYAN, A. Apresentação. In: KALOUSTIAN, S. M. (Org.). Família brasileira: a base de tudo. São Paulo: Cortez; Brasília (DF):UNICEF, 2000, p. 9-10.

MIOTO, R.C.T. Família e Serviço Social - contribuições para o debate. Revista Serviço Social \& Sociedade, nº 55, p.114-130, ano XVIII. São Paulo: Cortez, 1997.

NEDER, G. Ajustando o foco das lentes: um novo olhar sobre a organização das famílias no Brasil. In: KALOUSTIAN, S. M. (Org.). Família brasileira: a base de tudo. São Paulo: Cortez; Brasília (DF):UNICEF, 2000, p. 26-46.

SARTI, C.A. A família como espelho: um estudo sobre a moral dos pobres. Campinas: Autores Associados, 2003.

Serv. Soc. \& Saúde, Campinas, SP v. 12, n. 2 (16), p. 171-184, jul./dez. 2013 ISSN 1676-6806 
SIMIONATTO, I.; NOGUEIRA, V. M. Política de Saúde - do projeto formal à prática concreta. Serviço Social \& Sociedade. São Paulo: Cortez, n. 44, p. 53-60, 1994.

SYMANSKI, H. Teoria e 'teorias' de famílias. In: CARVALHO, M.C. B. (Org.). A família contemporânea em debate. São Paulo: Cortez, 2003, p. 23-27.

VASCONCELOS, A.M. A prática do Serviço Social: cotidiano, formação e alternativas na área de saúde. São Paulo: Cortez, 2002. 